\title{
BMJ Open Does practice analysis agree with the ambulatory care sensitive conditions' list of avoidable unplanned admissions?: a cross-sectional study in the East of England
}

To cite: Fleetcroft $\mathrm{R}$, Hardcastle A, Steel N, et al. Does practice analysis agree with the ambulatory care sensitive conditions' list of avoidable unplanned admissions?: a crosssectional study in the East of England. BMJ Open 2018;8:e020756. doi:10.1136/ bmjopen-2017-020756

- Prepublication history for this paper is available online. To view these files, please visit the journal online (http://dx.doi. org/10.1136/bmjopen-2017020756).

Received 21 November 2017 Revised 6 February 2018 Accepted 16 March 2018

\section{Check for updates}

${ }^{1}$ The Surgery, Acle Medical Partnership, Acle, UK ${ }^{2}$ Research and Development Department, The Queen Elizabeth Hospital King's Lynn NHS Foundation Trust, King's Lynn, UK

${ }^{3}$ Norwich Medical School, University of East Anglia, Norwich, UK

${ }^{4}$ School of Social and Community Medicine, University of Bristol, Bristol, UK

${ }^{5}$ NHS England Midlands \& East [East], Victoria House, Capital Park, Fulbourn, UK

${ }^{6}$ School of Medicine, Medical Sciences \& Nutrition, University of Aberdeen, Aberdeen, UK

Correspondence to Dr Robert Fleetcroft robert.fleetcroft@nhs.net

\section{ABSTRACT}

Objectives To use significant event audits (SEAs) in primary care to determine which of a sample of emergency (unplanned) admissions were potentially avoidable; and compare with the National Health Service (NHS) list of ambulatory care sensitive conditions (ACSCs). Design Analysis of unplanned medical admissions randomly identified in secondary care.

Setting Primary care in the East of England.

Participants 20 general practice teams trained to use SEA on unplanned admissions to identify potentially preventable factors.

Interventions SEA of admissions.

Main outcome measures Level of agreement between those admissions identified as potentially preventable by SEA and the NHS ACSC list.

Results $132(26 \%)$ of randomly selected patients with unplanned admissions gave consent and an SEA was performed by their primary practice team. 130 SEA reports had sufficient data for our analysis. Practices concluded that 17 (13\%) admissions were potentially preventable. The NHS ACSC list identified 36 admissions $(28 \%)$ as potentially preventable. There was a low level of agreement between the practices and the NHS list as to which admissions were preventable (kappa $=0.253$ ).

The ACSC list consisted mainly of respiratory admissions whereas the practice list identified a wider range of cases and identified context-specific factors as important. Conclusions There was disagreement between the NHS list and practice conclusions of potentially avoidable admissions. The SEAs suggest that the pathway into unplanned admission may be less dependent on the condition than on context-specific factors, and the assumption that unplanned admissions for ACSCs are reasonable indicators of performance for primary care may not be valid.

\section{INTRODUCTION}

'Emergency' admissions to hospital are unplanned-unlike elective admissions, which are planned for specific times and dates. There were 5.3 million unplanned

\section{Strengths and limitations of this study}

- We used actual cases of unplanned admissions which were examined soon after discharge.

- The unplanned admissions were randomly selected, and they were assessed by the practice team who looked after the patient at the time of admission.

- Training had been given to each practice to analyse the cases in a standardised way.

- Secondary care input to this process was limited to the discharge information received by primary care.

- This was a relatively small sample of unplanned admissions, and a larger sample will have provided more information on a greater range of conditions.

admissions to English hospitals in 2013 representing $67 \%$ of hospital bed days and costing $£ 12.5$ billion. ${ }^{1}$ In England, unplanned admissions have continued to rise by approximately $2 \%$ each year over the past decade. ${ }^{23}$ Unplanned admissions create difficulties for those responsible for planning and delivering services, and they are distressing for patients and their families. ${ }^{4}$

It is claimed that many medical 'unplanned' admissions could be prevented by being managed differently in primary care. Others have distinguished between avoidability (through having alternatives to admission at the time of event, eg, intermediate care) and preventability (through preventive actions usually in primary care, eg, maximising asthma control). ${ }^{5}$ The latter are called 'ambulatory care sensitive conditions' (ACSCs). ${ }^{6}$ National Health Service (NHS) England has defined ACSCs as conditions where effective community care and case management can help prevent the need for hospital admission, ${ }^{7}$ and these are currently used as a performance indicator for primary care. ${ }^{89}$ 


\begin{tabular}{|c|c|}
\hline ACSC group name & ICD-10 codes \\
\hline $\begin{array}{l}\text { Influenza and } \\
\text { pneumonia }\end{array}$ & $\begin{array}{l}\mathrm{J} 10, \mathrm{~J} 11, \mathrm{~J} 13, \mathrm{~J} 14, \mathrm{~J} 15.3, \mathrm{~J} 15.4 \\
\mathrm{~J} 15.7, \mathrm{~J} 15.9, \mathrm{~J} 16.8, \mathrm{~J} 18.1, \mathrm{~J} 18.8\end{array}$ \\
\hline $\begin{array}{l}\text { Other vaccine } \\
\text { preventable }\end{array}$ & $\begin{array}{l}\text { A35-A37, A80, B05, B06, B16.1, } \\
\text { B16.9, B18.0, B18.1, B26, G00.0, } \\
\text { M01.4 }\end{array}$ \\
\hline Asthma & $\mathrm{J} 45, \mathrm{~J} 46$ \\
\hline $\begin{array}{l}\text { Congestive heart } \\
\text { failure }\end{array}$ & I11.0, I50, J81 \\
\hline
\end{tabular}

\begin{tabular}{|c|c|}
\hline $\begin{array}{l}\text { Diabetes } \\
\text { complications }\end{array}$ & $\begin{array}{l}\text { E10.0-E10.8, E11.0-E11.8, E12.0- } \\
\text { E12.8, E13.0-E13.8, E14.0-E14.8 }\end{array}$ \\
\hline $\begin{array}{l}\text { Chronic obstructive } \\
\text { pulmonary disease }\end{array}$ & J20, J41-J44, J47 \\
\hline Angina & I20, I24.0, I24.8, I24.9 \\
\hline $\begin{array}{l}\text { Iron deficiency } \\
\text { anaemia }\end{array}$ & D50.1, D50.8, D50.9 \\
\hline Hypertension & $110,111.9$ \\
\hline $\begin{array}{l}\text { Nutritional } \\
\text { deficiencies }\end{array}$ & E40-E43, E55.0, E64.3 \\
\hline $\begin{array}{l}\text { Dehydration and } \\
\text { gastroenteritis }\end{array}$ & E86, K52.2, K52.8, K52.9 \\
\hline Pyelonephritis & N10-N12, N13.6 \\
\hline $\begin{array}{l}\text { Perforated/bleeding } \\
\text { ulcer }\end{array}$ & $\begin{array}{l}\text { K25.0-K25.2, K25.4-K25.6, K26.0- } \\
\text { K26.2, K26.4-K26.6, K27.0-K27.2, } \\
\text { K27.4-K27.6, K28.0-K28.2, K28.4- } \\
\text { K28.6 }\end{array}$ \\
\hline Cellulitis & $\begin{array}{l}\text { L03, L04, L08.0, L08.8, L08.9, L88, } \\
\text { L98.0 }\end{array}$ \\
\hline $\begin{array}{l}\text { Pelvic inflammatory } \\
\text { disease }\end{array}$ & N70, N73, N74 \\
\hline
\end{tabular}

\begin{tabular}{ll}
$\begin{array}{l}\text { Ear, nose and throat } \\
\text { infections }\end{array}$ & $\mathrm{H} 66, \mathrm{H} 67, \mathrm{~J} 02, \mathrm{~J} 03, \mathrm{~J} 06, \mathrm{~J} 31.2$ \\
$\begin{array}{ll}\text { Dental conditions } & \mathrm{A} 69.0, \mathrm{~K} 02-\mathrm{K} 06, \mathrm{~K} 08, \mathrm{~K} 09.8, \mathrm{~K} 09.9, \\
\mathrm{~K} 12, \mathrm{~K} 13\end{array}$ \\
$\begin{array}{l}\text { Convulsions and } \\
\text { epilepsy }\end{array}$ & $\mathrm{G} 40, \mathrm{G} 41, \mathrm{R} 56, \mathrm{O} 15$ \\
Gangrene & $\mathrm{R} 02$ \\
\hline
\end{tabular}

ACSC, ambulatory care sensitive condition; ICD-10,

International Classification of Diseases, 10th Revision.

In an attempt to reduce unplanned admissions, lists of ACSCs have been produced by many countries including the USA, Spain, the UK, Australia and New Zealand. ${ }^{10-14}$ The methodology used to identify lists of ACSCs typically includes consensus opinions of expert physician panels drawn from secondary and primary care, sometimes in conjunction with literature searches for guidelines in the best practice. ${ }^{61516}$

The current UKNHS list contains 19 conditions (focusing largely on medical rather than surgical conditions) where unplanned admission is thought to be potentially avoidable (table 1). ${ }^{9}$ This NHS list of ACSCs represents about $20 \%$ of all unplanned admissions in the UK, ${ }^{17}$ and is similar to other international lists of ACSCs, which constitute between $10 \%$ and $20 \%$ of all unplanned admissions. ${ }^{18}$ The NHS list was developed from previous lists of ACSCs in use in the USA ${ }^{19}$; it includes some conditions identified in a study based in England which used three expert panels. These panels included primary care and hospital clinicians, who reviewed a list of 174 disease codes (International Classification of Diseases, Ninth Revision) of clinical conditions related to unplanned admission. ${ }^{12} \mathrm{~A}$ consensus was then reached on those conditions where unplanned admission might have been prevented. Conditions were defined as a 'definite ACSC' if $70 \%$ or more of admissions were judged preventable by better prevention or by better management of that condition. However, the panels looked only at conditions, not patient-specific case details.

The extent to which unplanned admissions which have been identified as an ACSC can actually be prevented in practice is not known. ${ }^{20}$ A systematic review in 2000 reported a wide variation of estimates of the rates of unplanned admissions which were thought to be preventable, ranging from $<1 \%$ to $29 \%$ for unplanned admissions to medical wards in the UK. ${ }^{20}$

Overall, unplanned admission rates for ACSCs have been rising, increasing in England by $40 \%$ over the 10 years from 2001 to 2011, but not for all conditions; for example, rates of admissions for angina and congestive heart failure have fallen by $33 \%$, though rates for chronic obstructive pulmonary disease (COPD) have risen by $25 \%$ over this period. ${ }^{17}$

This literature, therefore, suggests that the ACSC approach may be oversimplistic. Another set of factors thought to contribute to unplanned admission is overall patient vulnerability, which may include both physical and mental comorbidities. ${ }^{21}$ Indeed, many risk prediction models are being developed to allow early interventions in community settings, and all of these use more factors than ACSC alone. ${ }^{22}$ There is another discourse about the availability of adequate services to support patients outside hospital in a period of deterioration where unplanned admissions may occur if additional local support cannot be put in place. ${ }^{23}$

Many studies use patient record review to look at pathways to admission that are potentially avoidable. Analysis of clinical records is already widely used in healthcare, examples being significant event audit (SEA) in primary care and root cause analysis in secondary care to examine unexpected outcomes and in identifying avoidable deaths. ${ }^{24-26}$ Research using hospital physicians and senior administrators performing detailed notes reviews of patients who have experienced an unplanned admission (rather than just diagnostic codes) has reported lower rates of preventability of admissions than the ACSC lists, at between $6 \%$ and $10 \% .{ }^{27-29}$ However, most of this research is based in secondary care, and there is little evidence of the primary care perspective on preventable admissions. ${ }^{20}$

We, therefore, aimed to fill this gap in the research by using a detailed notes review (SEA) by the primary care 
health team who had looked after that patient to identify potentially preventable factors in unplanned admissions; and then comparing the estimated avoidability of a list of unplanned admissions using two methods of assessment, those admissions deemed avoidable by the ACSC list and by a detailed notes review.

\section{METHODS}

This research was part of a National Institute for Health Research study titled 'Can a practice based approach using Significant Event Audit identify key factors that might reduce avoidable non-elective hospital admissions?'. One hundred and ten practices were approached in the Norfolk and Waveney area of East Anglia in the UK, and 20 practices were recruited. The practices included in the study were representative of English practices with respect to practice size and markers of deprivation, however, they were more likely to be rural. The practices included had a mean of 8640 registered adult patients (range 3362-16 148, national mean 8316). Seventy per cent practices were classified 'urban', $20 \%$ practices 'town and fringe' and $10 \%$ were 'rural' (national averages $85 \%$, $11 \%$ and $3 \%$, respectively). The mean Index of Multiple Deprivation score for practices was 21.1 (range 7.3-51.9, national mean 24.0, higher is more deprived).

These practices used one of three local hospitals for unplanned admissions, these being the James Paget University Hospitals NHS Foundation Trust, the Norfolk and Norwich University Hospitals NHS Foundation Trust and the Queen Elizabeth Hospital King's Lynn NHS Foundation Trust. Practices were recruited who were willing to discuss unplanned admissions from their own practice and carry out a type of case notes review called Significant event audit (SEA) on a subgroup of these patients after discharge. SEA entails a detailed review of individual case notes of patients by their practice team. We chose this approach because SEA is a technique which is already commonly used to analyse patient safety incidents and unexpected outcomes both by general practice for appraisal, although it is not routinely used to analyse unplanned admissions. SEA entails individual episodes being analysed in a systematic and detailed way by the practice team to ascertain what can be learnt about the overall quality of care, and to indicate any changes that might lead to future improvements. ${ }^{30}$

Each practice identified one lead clinician (usually a general practitioner (GP)) and one designated administrator who were responsible for running and facilitating SEA meetings within that practice, and writing SEA reports. The lead clinician and administrator attended one of two training sessions led by an experienced GP educator, where training was given both in their roles as practice facilitators of SEA and in writing a summary report for each case. This training was based on the guidance issued by the National Patient Safety Agency for the conduct of SEA, and this guidance is recommended by the Royal College of General Practitioners as best practice. ${ }^{30}$
Data on all unplanned admissions to medical wards were collected by a data clerk at the three participating hospitals; from these admissions, one was randomly identified for each practice in each week. The practice then approached that patient for consent to participate in the study.

Cases were discussed at the practice clinical meeting in primary care facilitated by the trained GP and administrator. A summary of each case was written up by the administrator with the guidance of the lead GP based on the salient points that have arisen from the practice clinical meeting. The report included information on how the immediate clinical decision to admit happened; whether the admission could have been avoided by factors under primary care control (yes or no); whether patient, practice or systems factors may have been contributory; what changes have been made to avoid this recurring; how long those changes would take to put in place and see their impact; in addition, how likely it was that similar circumstances could contribute to further admissions. Feedback was given to each practice on the quality of the SEA report after they had performed the first three SEAs.

The ICD-10 disease code for the primary cause of admission was identified for each unplanned admission determined at discharge from the hospital database so that the cases could be categorised into those with an ACSC and those without an ACSC. ${ }^{9}$ Preventability of each admission by the practice teams was based on their response to the question in the SEA form 'Whether the admission could have been avoided by factors under primary care control.'. An inter-rater reliability analysis using the Cohen's kappa statistic was performed to determine the consistency between admissions considered being preventable using the ACSC list and those considered to be preventable by a practice team using SEA. Both of these measures of preventable admissions are independent. These data were computed in SPSS Statistics V.22.

\section{Patient involvement}

We involved patients and public through the PPIRes group (public and patient involvement in research) in the design, application process and conduct of the research project that analysed the unplanned admissions. Earlier versions of this paper was discussed by the steering group meetings which included patient representatives. Research outputs will be disseminated though local networks to patients.

\section{RESULTS}

There were 3355 unplanned medical admissions to acute trusts from the participating 20 practices over the course of the study. Nineteen practices $(95 \%)$ completed the study; one practice withdrew due to new ownership and staff shortages. The practices had a mean of 8640 patients each (range 3362-16 148, SD 3864, national mean 8316), and a median Index of Multiple Deprivation 2010 of 19.72 (range 7.32-52.0, national mean 24, higher 
number indicates more deprived population). Data on rurality of practices reported that 14 practices were classified as 'urban', 4 practices were 'town and fringe' and 2 practices were 'village'. Out of the 507 patients randomly selected, 132 (26\%) gave their consent and an SEA was performed and a report written. In these SEA reports, data on preventability were missing for two patients, leaving 130 reports for analysis (98\%).

Table 2 displays the list of ICD-10 disease codes for each of 130 admissions in the study, whether the condition was included in the ACSC list, and whether the SEAs carried out by practices concluded that these admissions were potentially avoidable. Of these 130 admissions, the practices concluded that $17(13 \%)$ were potentially preventable by factors under primary care control. Using the NHS ACSC list of avoidable conditions, 36 admissions (28\%) were categorised to be potentially preventable. The interrater agreement coefficient, kappa, between avoidability conclusion by practices using SEA and preventability according to the NHS ACSC code was 0.253 , where a value of 1 represents perfect agreement, and a value of 0 represents no agreement 'above that which might be expected by chance'. Guides to interpretation of values of kappa suggest only 'fair' agreement between raters for 0.253 , and we would expect a moderate or substantial agreement with a kappa between 0.41 and $0.80 .{ }^{31-33}$ Put another way, in this series there was agreement in $75 \%$ of cases, which was only $8 \%$ above the expected agreement by chance of $67 \%$. Those admissions identified using the NHS ACSC list as potentially preventable mainly consisted of respiratory admissions, these being pneumonia 14 cases $(39 \%)$, COPD 5 cases $(14 \%)$, asthma 3 cases $(8 \%)$ and bronchiectasis 1 case $(3 \%)$. Practice teams identified fewer respiratory causes as potentially preventable-pneumonia four cases (24\%), asthma one case $(6 \%)$, COPD one case $(6 \%)$ and bronchiectasis one case $(6 \%)$. Practices identified a wider range of cases as potentially preventable including admission with codes for constipation, anxiety and cancer.

Table 3 lists the cases where there was disagreement between the ACSC list and SEA as to whether the admission could have been prevented. There were seven cases where SEA determined admission was avoidable, but the key causal factors identified were not on the ACSC list of preventable admissions. In these cases, SEA identified that patient factors were present in $6 / 7$, practitioner factors were present in $3 / 7$ cases and systems factors were present in $4 / 7$ cases. Free text comments also showed patient factors, such as presenting at A\&E rather than contacting their own GP; failure to seek timely advice from their GP in a case of sepsis and increasing shortness of breath and failing to attend routine diabetes check-up with their general practice, leading to a loss of control of diabetes. Comments for practitioner factors included, for example, failure to prescribe a PPI to a patient on aspirin, and admission by the Out of Hours (OOHs) service where the GP felt home management was feasible. Comments for systems factors included lack of communication between the practice and OOHs service in two cases. Five of these seven cases occurred outside normal working hours using the 'out-of-hours' services through 111.

Of the total 36 cases in our study in which the ACSC list identified an admission as potentially avoidable, there were $25(69 \%)$ cases in which the SEA did not. These included 5 cases of heart failure, 11 cases of lobar pneumonia, 2 cases of emphysema, 4 cases of COPD, 2 cases of asthma and 1 case of cellulitis. In these cases, SEA identified that patient factors leading to admission were present in $13 / 25$, practitioner factors were present in $2 / 25$ cases and systems factors were present in $6 / 25$ cases. Despite these factors being present, the judgement was that admission was not preventable.

\section{DISCUSSION}

\section{Statement of principal findings}

There was disagreement on which admissions might be avoidable when comparing the NHS ACSC list with the list generated by the practice teams using SEA. These findings suggest that the avoidability of unplanned admission may be more dependent on the context-specific factors than the condition. These findings also suggest that in some cases the context may be at least as important as or more important than the diagnosis. The current use of a diagnostic label to identify potentially avoidable admissions (such as the ACSC list) might be problematic as a diagnostic label does not allow for different levels of severity of the condition, influential comorbidities such as dementia, and at which point in time the admission may have been avoidable - the condition may have deteriorated beyond prevention of admission if left 'too late'. This may suggest that the assumption that unplanned admissions for ACSCs are reasonable indicators of performance for primary care may not be valid-for example, this indicator may reflect the availability and quality of social care rather than the quality of primary care. ${ }^{34}$ Our findings that many ACSC admissions may not be avoidable may also explain why ACSC-related unplanned admissions have continued to rise over the past years despite many efforts aimed to reduce these admissions. ${ }^{35}$

\section{Strengths and weaknesses of the study}

The strength of the study was the analysis of the review of the patients record rather than administrative and ICD codes, and this analysis was performed soon after discharge by the primary care team looking after the patient, and as far as we are aware this is the first time this approach has been used in primary care. The unplanned admissions were randomly selected, and they were assessed by the practice team who looked after the patient at the time of admission. The proportion of admissions which were on the ACSC list (28\%) is within the range identified in other studies and datasets ${ }^{19} 20$ and may be higher than most estimates due to our study addressing medical admissions only. Training had been given to a lead clinician and administrator from each practice to 
Table 2 Emergency admission ICD-10 codes for each of 130 patients included in this study, and whether their admission was thought to be potentially avoidable by two methods

\begin{tabular}{|c|c|c|c|}
\hline $\begin{array}{l}\text { ICD-10 } \\
\text { disease } \\
\text { codes }\end{array}$ & Description of disease codes & $\begin{array}{l}\text { Determined by SEA } \\
\text { to be potentially } \\
\text { avoidable? }\end{array}$ & $\begin{array}{l}\text { Included in the ACSC } \\
\text { list as potentially } \\
\text { avoidable? }\end{array}$ \\
\hline A08.3 & Other viral enteritis & No & No \\
\hline A09.0 & $\begin{array}{l}\text { Other and unspecified infectious gastroenteritis and colitis, of } \\
\text { infectious origin }\end{array}$ & No & No \\
\hline A09.9 & Infectious gastroenteritis and colitis, unspecified & No & No \\
\hline A41.8 & Other specified sepsis & No & No \\
\hline B35.3 & Tinea pedis & No & No \\
\hline C34.1 & Malignant neoplasm of upper lobe, bronchus or lung & No & No \\
\hline C34.1 & Malignant neoplasm of upper lobe, bronchus or lung & Yes & No \\
\hline C34.3 & Malignant neoplasm; lower lobe, bronchus or lung & No & No \\
\hline C34.3 & Malignant neoplasm; lower lobe, bronchus or lung & No & No \\
\hline C34.9 & Malignant neoplasm of bronchus and lung-unspecified & No & No \\
\hline C78.0 & Secondary malignant neoplasm of lung & No & No \\
\hline C79.5 & Secondary malignant neoplasm of bone and bone marrow & No & No \\
\hline C91.1 & Chronic lymphocytic leukaemia of B-cell type & No & No \\
\hline C91.1 & Chronic lymphocytic leukaemia of B-cell type & No & No \\
\hline C92.0 & Acute myeloblastic leukaemia & No & No \\
\hline $\mathrm{C} 97$ & Malignant neoplasms of independent (primary) multiple sites & No & No \\
\hline D32.9 & Benign neoplasm: meninges, unspecified & No & No \\
\hline D64.9 & Anaemia, unspecified & No & No \\
\hline E10.9 & Type 1 diabetes mellitus without complications & Yes & No \\
\hline F41.9 & Anxiety disorder, unspecified & Yes & No \\
\hline G20 & Parkinson's disease & No & No \\
\hline G20 & Parkinson's disease & No & No \\
\hline G43.9 & Migraine-migraine, unspecified & No & No \\
\hline $\mathrm{H} 81.3$ & Other peripheral vertigo & No & No \\
\hline 121.0 & Acute transmural myocardial infarction of anterior wall & No & No \\
\hline 121.0 & Acute transmural myocardial infarction of anterior wall & No & No \\
\hline 121.0 & Acute transmural myocardial infarction of anterior wall & No & No \\
\hline 121.1 & Acute transmural myocardial infarction of inferior wall & No & No \\
\hline 121.1 & Acute transmural myocardial infarction of inferior wall & No & No \\
\hline 121.1 & Acute transmural myocardial infarction of inferior wall & No & No \\
\hline 121.4 & Acute subendocardial myocardial infarction & No & No \\
\hline 121.9 & Acute myocardial infarction, unspecified & No & No \\
\hline 121.9 & Acute myocardial infarction, unspecified & No & No \\
\hline 121.9 & Acute myocardial infarction, unspecified & No & No \\
\hline 121.9 & Acute myocardial infarction, unspecified & No & No \\
\hline 121.9 & Acute myocardial infarction, unspecified & No & No \\
\hline 121.9 & Acute myocardial infarction, unspecified & No & No \\
\hline 121.9 & Acute myocardial infarction, unspecified & No & No \\
\hline 126.9 & Pulmonary embolism without mention of acute cor pulmonale & No & No \\
\hline 135.0 & Aortic (valve) stenosis & No & No \\
\hline 144.2 & Atrioventricular block, complete & No & No \\
\hline 146.0 & Cardiac arrest with successful resuscitation & No & No \\
\hline
\end{tabular}




\begin{tabular}{|c|c|c|c|}
\hline $\begin{array}{l}\text { ICD-10 } \\
\text { disease } \\
\text { codes }\end{array}$ & Description of disease codes & $\begin{array}{l}\text { Determined by SEA } \\
\text { to be potentially } \\
\text { avoidable? }\end{array}$ & $\begin{array}{l}\text { Included in the ACSC } \\
\text { list as potentially } \\
\text { avoidable? }\end{array}$ \\
\hline 146.9 & Cardiac arrest, unspecified & No & No \\
\hline 148 & Atrial fibrillation and flutter & No & No \\
\hline 148 & Atrial fibrillation and flutter & No & No \\
\hline 148 & Atrial fibrillation and flutter & No & No \\
\hline 148 & Atrial fibrillation and flutter & No & No \\
\hline 150.0 & Congestive heart failure & No & Yes \\
\hline 150.0 & Congestive heart failure & No & Yes \\
\hline 150.0 & Congestive heart failure & No & Yes \\
\hline 150.0 & Congestive heart failure & No & Yes \\
\hline 150.0 & Congestive heart failure & No & Yes \\
\hline 150.0 & Congestive heart failure & Yes & Yes \\
\hline 150.0 & Congestive heart failure & Yes & Yes \\
\hline 160.2 & $\begin{array}{l}\text { Subarachnoid haemorrhage from anterior communicating } \\
\text { artery }\end{array}$ & No & No \\
\hline 161.1 & Intracerebral haemorrhage in hemisphere, cortical & Yes & No \\
\hline 161.9 & Intracerebral haemorrhage, unspecified & No & No \\
\hline 163.5 & $\begin{array}{l}\text { Cerebral infarction due to unspecified occlusion or stenosis of } \\
\text { cerebral arteries }\end{array}$ & No & No \\
\hline 163.9 & Cerebral infarction, unspecified & No & No \\
\hline 163.9 & Cerebral infarction, unspecified & No & No \\
\hline 163.9 & Cerebral infarction, unspecified & No & No \\
\hline 164 & Stroke, not specified as haemorrhage or infarction & No & No \\
\hline 195.1 & Orthostatic hypotension & No & No \\
\hline J18.0 & Bronchopneumonia, unspecified & Yes & No \\
\hline J18.0 & Bronchopneumonia, unspecified & No & No \\
\hline J18.0 & Bronchopneumonia, unspecified & Data missing & No \\
\hline J18.1 & Lobar pneumonia, unspecified & Yes & Yes \\
\hline J18.1 & Lobar pneumonia, unspecified & No & Yes \\
\hline J18.1 & Lobar pneumonia, unspecified & No & Yes \\
\hline J18.1 & Lobar pneumonia, unspecified & No & Yes \\
\hline J18.1 & Lobar pneumonia, unspecified & No & Yes \\
\hline J18.1 & Lobar pneumonia, unspecified & No & Yes \\
\hline J18.1 & Lobar pneumonia, unspecified & No & Yes \\
\hline J18.1 & Lobar pneumonia, unspecified & No & Yes \\
\hline J18.1 & Lobar pneumonia, unspecified & No & Yes \\
\hline J18.1 & Lobar pneumonia, unspecified & No & Yes \\
\hline J18.1 & Lobar pneumonia, unspecified & No & Yes \\
\hline J18.1 & Lobar pneumonia, unspecified & Yes & Yes \\
\hline J18.1 & Lobar pneumonia, unspecified & No & Yes \\
\hline J18.1 & Lobar pneumonia, unspecified & Yes & Yes \\
\hline J18.9 & Pneumonia, unspecified & No & No \\
\hline J22 & Unspecified acute lower respiratory infection & No & No \\
\hline J22 & Unspecified acute lower respiratory infection & No & No \\
\hline J22 & Unspecified acute lower respiratory infection & No & No \\
\hline
\end{tabular}


Table 2 Continued

ICD-10

disease

codes

Description of disease codes

J43.9 Emphysema, unspecified

J43.9 Emphysema, unspecified

J44.0 Chronic obstruct pulmonary disease with acute lower respiratory infection

J44.0 Chronic obstruct pulmonary disease with acute lower respiratory infection

\begin{tabular}{|c|c|c|c|}
\hline $\mathrm{J} 44.1$ & $\begin{array}{l}\text { Chronic obstruct pulmonary diseases with acute } \\
\text { exacerbation, unspecified }\end{array}$ & No & Yes \\
\hline $\mathrm{J} 44.1$ & $\begin{array}{l}\text { Chronic obstruct pulmonary disease with acute exacerbation, } \\
\text { unspecified }\end{array}$ & Yes & Yes \\
\hline J44.1 & $\begin{array}{l}\text { Chronic obstruct pulmonary disease with acute exacerbation, } \\
\text { unspecified }\end{array}$ & No & Yes \\
\hline $\mathrm{J} 45.9$ & Asthma, unspecified & Yes & Yes \\
\hline J45.9 & Asthma, unspecified & No & Yes \\
\hline $\mathrm{J} 45.9$ & Asthma, unspecified & No & Yes \\
\hline $\mathrm{J} 47$ & Bronchiectasis & Yes & Yes \\
\hline J69.0 & Pneumonitis due to food and vomit & No & No \\
\hline J86.9 & Pyothorax-pyothorax without fistula & No & No \\
\hline J93.8 & Pneumothorax-other pneumothorax & No & No \\
\hline K22.2 & Oesophageal obstruction & No & No \\
\hline K26.3 & Duodenal ulcer, acute without haemorrhage or perforation & Yes & No \\
\hline K59.0 & Constipation & Yes & No \\
\hline K70.3 & Alcoholic cirrhosis of liver & No & No \\
\hline K70.3 & Alcoholic cirrhosis of liver & No & No \\
\hline K80.1 & Calculus of gallbladder with other cholecystitis & No & No \\
\hline K80.3 & Calculus of bile duct with cholangitis & No & No \\
\hline K83.0 & Cholangitis & No & No \\
\hline K92.2 & Gastrointestinal haemorrhage, unspecified & No & No \\
\hline L03.1 & Cellulitis of other parts of limb & No & Yes \\
\hline L03.1 & Cellulitis of other parts of limb & Yes & Yes \\
\hline L03.1 & Cellulitis of other parts of limb & Data missing & Yes \\
\hline L03.1 & Cellulitis of other parts of limb & Yes & Yes \\
\hline L40.0 & Psoriasis vulgaris & No & No \\
\hline N39.0 & Urinary tract infection, site not specified & No & No \\
\hline N39.0 & Urinary tract infection, site not specified & No & No \\
\hline R10.3 & Pain localised to other parts of lower abdomen & No & No \\
\hline $\mathrm{R} 10.3$ & Pain localised to other parts of lower abdomen & No & No \\
\hline R11 & Nausea and vomiting & No & No \\
\hline R29.6 & Tendency to fall, not elsewhere classified & No & No \\
\hline R33 & Retention of urine & No & No \\
\hline R50.9 & Fever, unspecified & No & No \\
\hline R51 & Headache & No & No \\
\hline R55 & Syncope and collapse & No & No \\
\hline R63.4 & Abnormal weight loss & No & No \\
\hline S01.0 & Open wound of scalp & No & No \\
\hline
\end{tabular}

Continued

Included in the ACSC list as potentially avoidable?

\section{avoidable?}

Yes

Yes

Yes

Yes

No Yes

No Yes

Yes

Determined by SEA

No

No Yes

\section{Yes}

(a)

Yes




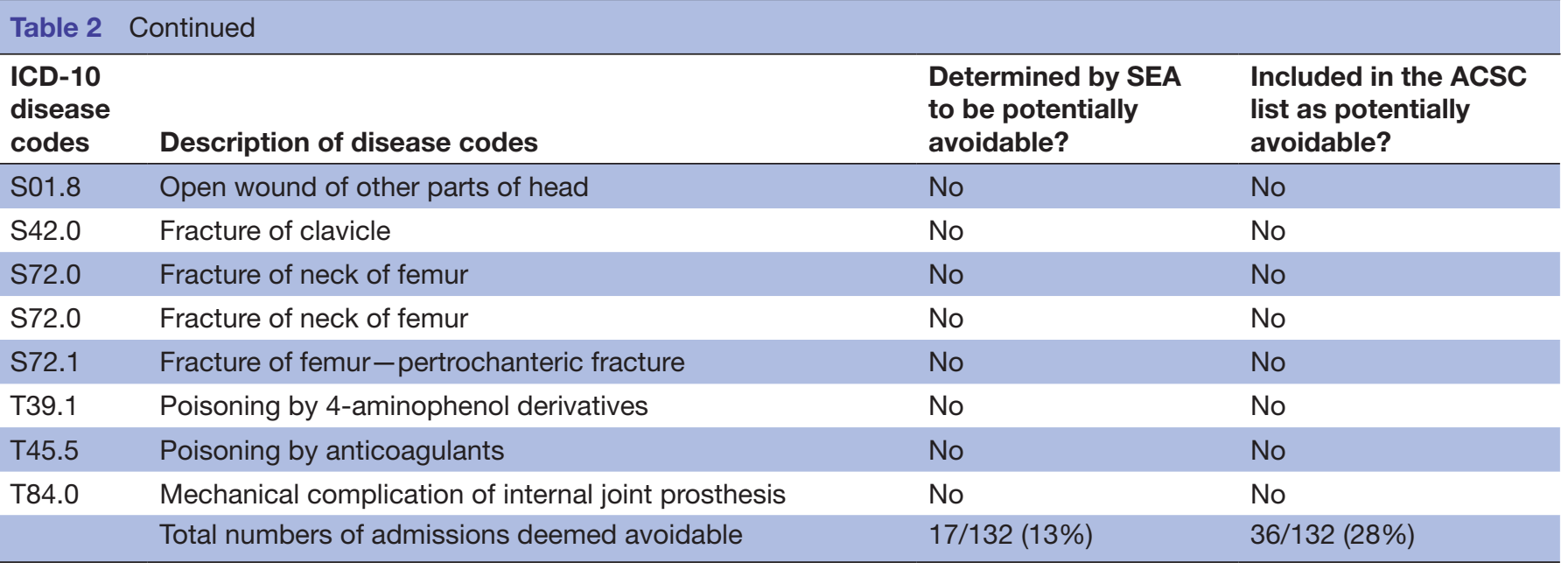

ACSC, ambulatory care sensitive condition; ICD-10, International Classification of Diseases, 10th Revision; SEA, significant event audit.

analyse the cases in a standardised way, and feedback on the standard of SEA report was given to practices early in the study. The sample of practices was generally representative of the demography of English practices. Weaknesses include that the secondary care input to this process was limited to the discharge information received by primary care, and there was no input from the patient or where relevant the emergency services. This was a relatively small sample of unplanned admissions, and a larger sample will have provided more information on a greater range of conditions, on the types of preventable admission and what factors may be involved. Only $26 \%$ of randomly identified cases were analysed, this was mainly due to difficulties with gaining consent from patients, which

Table 3 Cases where there were disagreement on preventability of admission, and whether patient practitioner or systems factors were identified in each case

\begin{tabular}{|c|c|c|c|c|c|c|c|}
\hline $\begin{array}{l}\text { ICD-10 } \\
\text { code for } \\
\text { unplanned } \\
\text { admission }\end{array}$ & Description of disease codes & $\begin{array}{l}\text { Total } \\
\text { number } \\
\text { of cases }\end{array}$ & $\begin{array}{l}\text { Case } \\
\text { determined } \\
\text { by SEA to be } \\
\text { potentially } \\
\text { avoidable? }\end{array}$ & $\begin{array}{l}\text { Condition } \\
\text { on the } \\
\text { ACSC list as } \\
\text { avoidable? }\end{array}$ & $\begin{array}{l}\text { Number of } \\
\text { cases where } \\
\text { patient } \\
\text { factors } \\
\text { contributed } \\
\text { to admission? }\end{array}$ & $\begin{array}{l}\text { Number of } \\
\text { cases where } \\
\text { practitioner } \\
\text { factors } \\
\text { contributed } \\
\text { to } \\
\text { admission? }\end{array}$ & $\begin{array}{l}\text { Number of } \\
\text { cases where } \\
\text { system } \\
\text { factors } \\
\text { contributed } \\
\text { to } \\
\text { admission? }\end{array}$ \\
\hline 150.0 & Congestive heart failure & 5 & $0 / 5$ & $5 / 5$ & $1 / 5$ & $0 / 5$ & $1 / 5$ \\
\hline J18.1 & Lobar pneumonia, unspecified & 11 & $0 / 11$ & $11 / 11$ & $5 / 11$ & $0 / 11$ & $1 / 11$ \\
\hline J43.9 & Emphysema, unspecified & 2 & $0 / 2$ & $2 / 2$ & $2 / 2$ & $1 / 2$ & $2 / 2$ \\
\hline $\mathrm{J} 44.0$ & $\begin{array}{l}\text { Chronic obstruct pulmonary disease with } \\
\text { acute lower respiratory infection }\end{array}$ & 2 & $0 / 2$ & $2 / 2$ & $2 / 2$ & $0 / 2$ & $0 / 2$ \\
\hline J44.1 & $\begin{array}{l}\text { Chronic obstruct pulmonary diseases with } \\
\text { acute exacerbation, unspecified }\end{array}$ & 2 & $0 / 2$ & $2 / 2$ & $2 / 2$ & $0 / 2$ & $2 / 2$ \\
\hline E10.9 & $\begin{array}{l}\text { Type } 1 \text { diabetes mellitus without } \\
\text { complications }\end{array}$ & 1 & Yes & No & Yes & No & Yes \\
\hline F41.9 & Anxiety disorder, unspecified & 1 & Yes & No & Yes & Yes & Yes \\
\hline 161.1 & $\begin{array}{l}\text { Intracerebral haemorrhage in hemisphere, } \\
\text { cortical }\end{array}$ & 1 & Yes & No & Yes & No & Yes \\
\hline K26.3 & $\begin{array}{l}\text { Duodenal ulcer, acute without } \\
\text { haemorrhage or perforation }\end{array}$ & 1 & Yes & No & No & No & No \\
\hline K59.0 & Constipation & 1 & Yes & No & Yes & Yes & No \\
\hline
\end{tabular}

ACSC, ambulatory care sensitive condition; ICD-10, International Classification of Diseases, 10th Revision; SEA, significant event audit. 
according to practices was caused by a combination of logistics (the study required signed patient consent); perceived concern about distress from the concept of an admission being 'avoidable' and patients whom the practice felt were too unwell in the aftermath of an admission to wish to be involved. There was variation in the quality of the competed SEA report, and as the SEA meetings were confidential to the practice and not observed, it was not possible to draw conclusions about the quality of the conduct of the SEA meetings within each practice. Practices in the study were representative of English practices in terms of size and markers of deprivation, although they were more likely to be rural. It is possible that practices recruited into this study may differ in other ways from those who declined to take part. The low proportion of patients consenting may also have introduced bias.

\section{Strengths and weaknesses in relation to other studies, discussing important differences in results}

Most work on ACSCs uses panels of physicians examining diagnostic codes only, which risks leading to forming theories and conclusions without taking into account the individual factors surrounding the admission. Our research concurs with others using a similar approach of case-based analyses, which have reported lower rates of preventable admission compared with those predicted, by using ACSC lists. ${ }^{27-29}$ Our findings question the validity of the current list of NHS ACSC codes, and others have questioned the assumption that unplanned admissions for ACSCs are reasonable indicators of performance. ${ }^{34}$

\section{Meaning of the study: possible explanations and implications for clinicians and policy-makers}

The ACSC list used by the NHS is not reproducible in this small-scale study when unplanned admissions are examined in a detailed and systematic way by primary care teams caring for these patients. This may have international relevance, as similar lists of ACSCs are used in other countries. Preventable admissions identified in this study by primary care are less frequent than those determined from the current NHS list of ACSCs, although this was a relatively small study, and there is a need for larger scale study to confirm these findings. Lists of preventable admissions may more usefully classified by processes (such as drug error, failure of follow-up) than diagnostic codes which may be a blunt instrument. The NHS should consider not using the current list of ACSCs for performance management of unplanned admissions, at least until a more robust list has been developed and validated. Any new criteria should draw on data from actual cases and involve all relevant providers of healthcare and patients.

\section{Unanswered questions and future research}

A larger study of similar design including the views of patients, secondary care and also the emergency services (when they were involved in admission) would be able to produce an updated and comprehensive list of preventable admissions and the processes involved, and also validate our findings. This would inform efforts to reduce unplanned admission by identifying context-specific factors related to admission, which current ACSC lists do not provide.

Acknowledgements We are very grateful to the Norfolk and Suffolk Primary andCommunity Care Research Office, the Sponsor NHS South Norfolk CCG, Public andPatient Involvement in Research (PPIRes) and the two patient representatives,the participating general practices, hospitals and patients for their help with theoriginal study.

Contributors RF: original idea for the study, supervised all aspects of the research, led the stakeholder liaison process, study design, data analysis and interpretation of results, and led the drafting of the paper. He is the guarantor. AHa: senior research associate for this study; responsible for the day-to-day running of the study, including steering committee, data collection and interpretation, and manuscript preparation. PKM, SP, AL, NS, AHo: study design, steering committee, data interpretation and manuscript preparation. GMP: lead statistician for the study; study design, steering committee, data analysis and interpretation, and manuscript preparation.

Funding This paper presents independent research funded by the National Institute for Health Research (NIHR) under its Research for Patient Benefit (RfPB) Programme (grant reference number PB-PG-0212-27059).

Disclaimer The views expressed are those of the author(s) and not necessarily those of the NHS, the NIHR or the Department of Health. The funders had no role in the study design and the collection, analysis, and interpretation of data and the writing of the article and the decision to submit it for publication. All researchers had full access to all of the data.

Competing interests All authors received a research grant from the National Institute for Health Research who funded this study and in addition to this: NS, GMP and RF report other grants from National Institute for Health Research, during the conduct of the study. AL, AHo, AHa, SP and PKM have nothing to disclose.

Patient consent Not required.

Ethics approval Ethics approval was granted by National Research Ethics Committee East of England, ref 13/EE/0328.

Provenance and peer review Not commissioned; externally peer reviewed. Data sharing statement Data used in this research are presented in table 2.

Open Access This is an Open Access article distributed in accordance with the terms of the Creative Commons Attribution (CC BY 4.0) license, which permits others to distribute, remix, adapt and build upon this work, for commercial use, provided the original work is properly cited. See: http://creativecommons.org/ licenses/by/4.0/

(C) Article author(s) (or their employer(s) unless otherwise stated in the text of the article) 2018. All rights reserved. No commercial use is permitted unless otherwise expressly granted.

\section{REFERENCES}

1. National Audit Office. Emergency admissions to hospital: managing the demand: the stationary office, 2013.

2. Department of Health. A\&E Activity and Emergency Admissions statistics, NHS and independent sector organisations in England. Redditch: NHS England, 2015.

3. NHS England. Emergency admissions for ambulatory care sensitive conditions - characteristics and trends at national level. 2014 https:// www.england.nhs.uk/wp-content/uploads/2014/03/red-acsc-emadmissions-2.pdf (accessed 18 Nov 2015).

4. Purdy S, Griffin T. Reducing hospital admissions. BMJ 2008;336:4-5.

5. O'Cathain A, Knowles E, Maheswaran R, et al. A system-wide approach to explaining variation in potentially avoidable emergency admissions: national ecological study. BMJ Qual Saf 2014;23:47-55.

6. Billings J, Zeitel L, Lukomnik J, et al. Impact of socioeconomic status on hospital use in New York City. Health Aff 1993;12:162-73.

7. NHS England. Emergency admissions for ambulatory care sensitive conditions. 2014 https://www.england.nhs.uk/wp-content/uploads/ 2014/03/red-acsc-em-admissions-2.pdf (accessed 11 Oct 2016).

8. NHS Institute of Innovation and Improvement. NHS Better care, better value indicators. 2016 http://www.productivity.nhs.uk/PCT_ 
Dashboard/DetailedView? percentileld=3\&yearQtrld=23\&indicatorld $=608 \&$ indicatorTypeld $=2 \&$ practiceGroupld $=0 \&$ tablndex $=0 \&$ compone $\mathrm{ntld}=0 \% 20-\% 20$ treatmentfunctionlist (accessed 11 Oct 2016).

9. Anon. Indicator construction: managing variation in emergency admissions. 2013 www.productivity.nhs.uk/Download/ TechnicalDefinition/608 (accessed 17 Nov 2015).

10. Bindman AB, Grumbach K, Osmond D, et al. Preventable hospitalizations and access to health care. JAMA 1995;274:305-11.

11. Caminal J, Starfield B, Sánchez E, et al. The role of primary care in preventing ambulatory care sensitive conditions. Eur J Public Health 2004;14:246-51.

12. Sanderson C, Dixon J. Conditions for which onset or hospital admission is potentially preventable by timely and effective ambulatory care. J Health Serv Res Policy 2000;5:222-30.

13. Page A, Ambrose S, Glover J, et al. Atlas of avoidable hospitalisations in Australia: ambulatory care-sensitive conditions. Cat. no. HSE 49. Canberra: AlHW, 2007.

14. Anon. Adult ambulatory sensitive hospitalisations. $2015 \mathrm{http} / / /$ www.hqsc.govt.nz/our-programmes/health-quality-evaluation/ projects/atlas-of-healthcare-variation/adult-ambulatory-sensitivehospitalisations/ (accessed 17 Nov 2015).

15. Agency for Healthcare Research and Quality. Ambulatory care sensitive conditions. Rockville: U.S. Department of Health \& Human Services, 2014

16. NHS Institute of Innovation and Improvement. Directory of ambulatory emergency care for adults: NHS Institute of Innovation and Improvement: Coventry, 2012.

17. Blunt I. Focus on preventable admissions. London: Health Foundation, 2013:5.

18. Agency for Healthcare Reseach and Quality. Four million hospital admissions potentially unnecessary. $2010 \mathrm{http} / / /$ archive.ahrq.gov/ news/newsroom/news-and-numbers/110310.html (accessed 18 Nov 2015).

19. Purdy S, Griffin T, Salisbury C, et al. Ambulatory care sensitive conditions: terminology and disease coding need to be more specific to aid policy makers and clinicians. Public Health 2009;123:169-73.

20. McDonagh MS, Smith DH, Goddard M. Measuring appropriate use of acute beds. A systematic review of methods and results. Health Policy 2000;53:157-84.

21. Salisbury C, Johnson L, Purdy S, et al. Epidemiology and impact of multimorbidity in primary care: a retrospective cohort study. $\mathrm{Br} J$ Gen Pract 2011;61:e12-21.
22. Wallace $\mathrm{E}$, Stuart $\mathrm{E}$, Vaughan $\mathrm{N}$, et al. Risk prediction models to predict emergency hospital admission in community-dwelling adults: a systematic review. Med Care 2014;52:751-65.

23. Purdy S, Paranjothy S, Huntley A, et al. Interventions to reduce unplanned hospital admission: a series of systematic reviews, 2012.

24. Hogan H, Healey F, Neale G, et al. Preventable deaths due to problems in care in English acute hospitals: a retrospective case record review study. BMJ Qual Saf 2012;21:737-45.

25. Clinical Effectiveness and Evaluation Unit. Why asthma still kills: the National Review of Asthma Deaths (NRAD). https://www.rcplondon. ac.uk/sites/default/files/why-asthma-still-kills-full-report.pdf (accessed 11 Jun 2015).

26. Knight M, Tuffnell D, Kenyon S, et al. Saving lives, improving mothers' care. 2015 https://www.npeu.ox.ac.uk/downloads/files/ mbrrace-uk/reports/MBRRACE-UK\%20Maternal\%20Report\% 202015.pdf (accessed 02 Mar 2016).

27. Bigby J, Dunn J, Goldman L, et al. Assessing the preventability of emergency hospital admissions. A method for evaluating the quality of medical care in a primary care facility. Am J Med 1987;83:1031-6.

28. Solberg LI, Peterson KE, Ellis RW, et al. The Minnesota project: a focused approach to ambulatory quality assessment. Inquiry 1990;27:359-67.

29. Martin I, Mason M, Mason D, et al. Emergency admissions: a journey in the right direction? 2007 http://www.ncepod.org.uk/2007report1/ Downloads/EA_report.pdf (accessed 19 Nov 2015).

30. Pringle M, Bowie P. Significant event audit; guidance for primary care teams. 2008 http://www.nrls.npsa.nhs.uk/resources/?entryid45= 61500 (accessed 19 Nov 2015).

31. Landis JR, Koch GG. The measurement of observer agreement for categorical data. Biometrics 1977;33:159-74.

32. Altman DG. Practical statistics for medical research. London: Chapman \& Hall/CRC, 1991:405.

33. Viera AJ, Garrett JM. Understanding interobserver agreement: the kappa statistic. Fam Med 2005;37:360-3.

34. Bardsley M, Blunt I, Davies S, et al. Is secondary preventive care improving? Observational study of 10-year trends in emergency admissions for conditions amenable to ambulatory care. BMJ Open 2013;3.

35. Blunt I, Bardsley M. Analyses of ambulatory care-sensitive conditions: The Kings Fund, 2012. 